\title{
PENURUNAN AKTIVITAS GIBBERELIN OLEH DAMINOZIDE PADA TANAMAN KRISAN (CRYSHANTHEMUM Sp.)
}

\section{REDUCTION OF GIBBERELLIN'S ACTIVITY BY DAMINOZIDE ON CRYSHANTHEMUM PLANT}

\author{
Tristi Indah Dwi Kurnia ${ }^{1)}$, Fuad Ardiyansyah ${ }^{2)}$ \\ 1), 2) Universitas PGRI Banyuwangi \\ tristi.indah@yahoo.com \\ diterima : 16 Juli 2020; dipublikasi : 31 Oktober 2020 \\ DOI: $10.32528 /$ bioma.v5i2.4011
}

\begin{abstract}
ABSTRAK
Tujuan dari penelitian ini adalah untuk mengetahui pengaruh penggunaan Daminozide dalam pembentukan Bunga Krisan pot pada aktivitas Gibberelin sebagai salah satu indikatornya dan untuk mengetahui Dosis Daminozide yang paling tepat dalam menurunkan aktivitas Gibberelin. Penelitian ini menggunakan rancangan faktorial dan disusun secara lengkap. Rancangan Acak Lengkap (RAL) yang terdiri dari dua faktor perlakuan yakni Varietas Krisan dan konsentrasi Daminozide dengan tiga kali ulangan. Hasil dari penelitian menunjukkan Daminozide terbukti mampu menekan pertumbuhan tinggi tanaman dengan cara menghambat sintesis Giberelin. Penggunaan Daminozide terbukti berpengaruh terhadap aktivitas Gibberelin yang ditunjukkan dengan menurunnya tinggi tanaman, meningkatnya diameter batang tanaman dan menurunnya kandungan Gibberelin pada semua varietas Krisan dan konsentrasi daminozide yang terbaik dalam menurunkan aktivitas Gibberelin dalam upaya membentuk Bunga Krisan pot agar memiliki masa simpan yang lebih panjang adalah sebesar $4500 \mathrm{ppm}$.
\end{abstract}

Kata Kunci : Daminozide, Morfologis, Krisan, Gibberelin

\begin{abstract}
The purpose of this study is 1) to determine the effect of the use of Daminozide in the formation of Chrysanthemum flower pots on Gibberelin activity as one indicator. And 2) To find out the most appropriate dose of Daminozide in reducing Gibberelin activity. This research uses factorial design and is arranged in full. A Completely Randomized Design (CRD) consisting of two treatment factors namely Chrysanthemum Variety and Daminozide concentration with three replications. The results of the study showed that Daminozide was able to suppress plant height growth by inhibiting the synthesis of Gibberellins. The use of Daminozide has been proven to have an effect on Gibberelin activity as indicated by decreasing plant height, increasing plant stem diameter and decreasing Gibberelin content in all Chrysanthemum varieties and the best daminozide concentration in reducing Gibberelin activity in an effort to form potted Chrysanthemum flowers in order to have a longer shelf life is equal to $4500 \mathrm{ppm}$
\end{abstract}

Key Words :Daminozide, Morphological, Cyhshanthemum, Gibberelin

Tristi Indah.,et al, Penurunan Aktivitas ... 


\section{PENDAHULUAN}

Bunga Krisan yang dikenal dengan istilah "Queen Of The East" merupakan salah satu bunga yang memiliki posisi sangat penting dalam keanekaragaman bunga komersial dunia. Permintaan pasar terhadap bunga Krisan dari tahun ke tahun mengalami peningkatan, ini dikarenakan Krisan memiliki bentuk yang indah serta warna yang beraneka ragam. Sebagai bunga komersial, selama ini Krisan banyak dimanfaatkan sebagai bunga potong. Bunga potong krisan mempunyai peluang pasar yang sangat luas. Pasar potensial yang dapat diharapkan adalah pasar-pasar yang ada di kota-kota besar, seperti Jakarta, bandung, Malang dan Denpasar. Permintaan untuk kebutuhan bahan dekorasi restorant, akntor, hotel maupun rumah tempat tinggal. Perilaku masyarakat dikota besar dalam menyambut hari-hari spesial maupun hari-hari Natal, tahun baru dan lebaran membuat permintaan terhadap bunga krisan dan bunga potong lainnya semakin bertambah. Sebagai gambaran dapat dijelaskan bahwa untuk wilayah Jakarta permintaan bunga potong meningkat rata-rata 10\%. (Balithi, 2016). Sebagai bunga potong, krisan memiliki masa simpan yang singkat yakni hanya 5-8 hari setelah dipotong, selanjutnya warna mahkota bunga krisan akan memudar dan mengalami kerontokan. Sehingga diperlukan suatu upaya untuk meningkatkan masa simpan bunga Krisan salah satunya adalah dengan pembentukan keragaan Bunga Krisan pot dengan menggunakan penggunaan zat penghambat tumbuh (Retardant) berupa Daminozide.

Daminozide adalah salah satu senyawa yang termasuk dalam salah satu zat penghambat tumbuh yang digunakan untuk menghambat aktivitas tumbuh suatu tanaman dengan cara mempengaruhi proses fisiologis yang ada pada tanaman. Daminozide yang bersisi senyawa-senyawa organik sintetik yang diberikan pada tanaman yang responsive akan menghambat perpanjangan sel pada meristem sub apikal, mengurangi laju perpanjangan batang tanpa mempengaruhi pertumbuhan dan perkembangan daun atau tanpa mendorong pertumbuhan yang abnormal (Wattimena, 1988). Mekanisme Pengaturan pertumbuhan diawali dengan menghambat biosintesa giberelllin (GA) sehingga akan berpengaruh terhadap pertumbuhan ruas-ruas batang suatu tanaman yang pada akhirnya menghambat penambahan tinggi tanaman. 
Tanaman Krisan merupakan tanaman perdu dengan tinggi maksimal dapat mencapai $120 \mathrm{~cm}$. Kumar (2019) dalam penelitiannya menyebutkan bahwa pengelompokkan variasi bunga Krisan didasarkan pada warna, corak, bentuk dan ukuran mahkota bunga Krisan. Varietas Bunga Krisan yang paling banyak dimanfaatkan adalah puma, reagent, dan giant. Rendahnya masa simpan bunga krisan potong yang berkisar hanya 5-8 hari, mendorong perlunya suatu upaya untuk memanipulasi pertumbuhan tanaman Krisan potong menjadi bunga krisan pot sehingga memiliki masa simpan yang lebih panjang yakni 14 sampai 20 hari. Penggunaan zat penghambat tumbuh berupa Daminozide diharapkan mampu membentuk keragaan bunga krisan pot dengan cara menghambat aktivitas Gibberelin pada suatu tanaman. Tujuan dari penelitian ini adalah 1)untuk mengetahui pengaruh penggunaan Daminozide dalam pembentukan Bunga Krisan pot pada aktivitas Gibberelin sebagai salah satu indikatornya. Dan 2)Untuk mengetahiu Dosis Daminozide yang paling tepat dalam menurunkan aktivitas Gibberelin.

\section{METODE}

Penelitian ini telah dilakukan di Green House yang berada di Desa Licin Kabupaten Banyuwangi. Dengan ketinggian tempat yakni $850 \mathrm{~m}$ dpl. Suhu harian berkisar antara $22-25^{\circ}$ C. Penelitian ini adalah penelitian eksperimen. Bahan Penelitian yang digunakan pada penelitian ini adalah5 varietas tanaman Krisan serta Daminozide dengan konsentrasi 0 ppm, 1500 ppm, 2500 ppm, 3500 ppm, 4500 ppm dan 5500 ppm. Alat yang digunakan dalam penelitian ini adalah alat tulis, peralatan pertanian, meteran, jangka sorong, camera digital, hand refractometer. Penelitian ini menggunakan rancangan faktorial dan disusun secara lengkap. Rancangan Acak Lengkap (RAL) yang terdiri dari dua faktor perlakuan dengan tiga kali ulangan. Faktor pertama yaitu 5 varietas tanaman Krisan (V), yakni :V1 ( varietas Red Remix), V2 (varietas Reagent Pink), V3 (varietas Yellow Puma), V4 (varietas Giant White) dan V5 (Varietas Giant Yellow). Sedangkan Faktor kedua adalah konsentrasi Daminozide (K) yang terdiri dari 6 level yakni : K0 ( konsentrasi Daminozide 0 ppm), K1 ( konsentrasi Daminozide 1500 ppm), K2 (konsentrasi Daminozide 2500 ppm), K3 (konsentrasi Daminozide 3500 ppm), K4 (konsentrasi Daminozide 4500 ppm) dan K5 (konsentrasi Daminozide 5500 ppm). 
Parameter penelitian yang diamati adalah tinggi tanaman, diameter batang tanaman , dan kandungan Gibberellin pada tanaman. Data yang diperoleh akan dianalisis menggunakan analisis sidik ragam pada Microsoft Excel 2007. Selanjutnya uji beda nyata akan diuji dengan Uji Duncan dengan taraf $5 \%$.

\section{Pelaksanaan Penelitian}

Penelitian ini telah dilaksanakan diawali dengan persiapan aplikasi Daminozide pada bibit tanaman Krisan yang telah berusia 3 minggu setelah tanam. Selanjutnya diulangi pada saat tanaman berusia 4 minggu setelah tanam. Kegiatan pemupukan dan pemeliharaan dilakukan sesuai dengan standar Standar Prosedur Operasional Budidaya Krisan Potong (2005) yakni diperlukan suatu kegiatan Disbudding yakni suatu kegiatan yang mengurangi jumlah tunas bunga agar nantinya jumlah mahkota bunga tidak terlalu banyak. Dalam upaya untuk menghambat aktivitas Gibberelin, maka dilakukan penyungkupan pada saat tanaman telah berusia 10 minggu setelah tanam atau saat tanaman Krisan sudah mulai membentuk calon tunas bunga. Hal ini dilakukan agar tanaman Krisan segera masuk ke fase generatif dan fase vegetatif terhenti. Pengukuran parameter penelitian diambil sejak tanaman berumur 15 hari setelah tanam. Uji kandungan Gibberellin diambil secara destruktif pada ekstrak tanaman saat panen.

\section{HASIL DAN PEMBAHASAN}

Dalam upaya mengetahui aktivitas Gibberelin, maka indikator yang dapat diketahui adalah dari parameter tinggi Tanaman. Daminozide diketahui dapat menghambat sintesis Giiberelin pada organ tanaman. Sehingga aktivitas pertumbuhan tanaman juga akan terhambat. Pada Penelitian ini, hasil tinggi tanaman saat panen diujikan dengan Uji Duncan dan didapatkan hasil berikut ini :

Tabel 1.Tinggi Tanaman saat Panen Tanaman Krisan dengan Penambahan Konsentrasi Daminozide Yang Berbeda

\begin{tabular}{cccccc}
\hline Perlakuan & \multicolumn{4}{c}{ Varietas Tanaman Krisan } \\
Konsentrasi & Red & Reagen & Yellow & Giant & Giant \\
Daminozide & Remix & Pink & Puma & White & Yellow \\
\hline
\end{tabular}




\begin{tabular}{|c|c|c|c|c|c|c|c|c|c|c|}
\hline \multirow{3}{*}{$\begin{array}{c}\text { Perlakuan } \\
\text { Konsentrasi } \\
\text { Daminozide }\end{array}$} & \multicolumn{9}{|c|}{ Varietas Tanaman Krisan } & \\
\hline & Red & & Reagen & & Yellow & & Giant & & Giant & \\
\hline & Remix & & Pink & & Puma & & White & & Yellow & \\
\hline 0 ppm & 41.61 & hi & 54.43 & 1 & 40.27 & gh & 43.07 & ij & 48.17 & $\mathrm{k}$ \\
\hline 1500 ppm & 32.30 & d & 44.57 & $\mathrm{j}$ & 33.93 & $\mathrm{e}$ & 40.30 & gh & 39.23 & $\mathrm{~g}$ \\
\hline 2500 ppm & 28.94 & $\mathrm{c}$ & 41.30 & hi & 32.00 & d & 39.10 & $\mathrm{~g}$ & 35.20 & $\mathrm{f}$ \\
\hline 3500 ppm & 25.87 & $\mathrm{~b}$ & 42.63 & $\mathrm{i}$ & 29.73 & $\mathrm{c}$ & 31.47 & d & 31.27 & $d$ \\
\hline 4500 ppm & 26.02 & $\mathrm{~b}$ & 32.90 & de & 28.80 & $\mathrm{c}$ & 29.37 & $\mathrm{c}$ & 27.60 & bc \\
\hline 5500 ppm & 27.56 & $b c$ & 29.23 & $\mathrm{c}$ & 27.20 & bc & 27.27 & bc & 24.20 & $\mathrm{a}$ \\
\hline
\end{tabular}

Keterangan: Nilai pada baris dan kolom yang sama yang diikuti oleh huruf yang berbeda menunjukkan berbeda nyata berdasarkan uji DMRT pada taraf $5 \%$.

Penggunaan Daminozide terbukti efektif secara morfologis dalam menghambat pertumbuhan tanaman dan secara fisiologis dalam penghambatan aktivitas hormon endogen Gibberelin pada tanaman Krisan. Dari data diatas dapat diketahui bahwa pada varietas Yellow Puma, peningkatan konsentrasi Daminozide hingga 5500 ppm dapat menurunkan tinggi tanaman Krisan hingga mencapai 30\% bila dibandingkan tinggi tanaman tanpa Daminozide. Hal ini sesuai dengan hasil penelitian Salachna (2017) yang menyatakan bahwa penambahan Daminozide dalam bentuk spray terbukti dapat menghambat tinggi tanaman Eucomis autumnalis (Mill.) Chitt sebesar 17\&\% bila dibandingkan dengan tanpa Daminozide.

Diameter batang tanaman merupakan salah satu indikator morfologis untuk dapat mengetahui penurunan aktivitas Gibberellin dengan adanya penggunaan Daminozide. Diameter batang tanaman Krisan dengan adanya pengaplikasian Daminozide dapat dilihat pada Tabel berikut ini : 
Tabel 2. Rata-rata Diameter Batang $(\mathrm{cm})$ Tanaman dengan Adanya Interaksi Konsentrasi Daminozide dan varietas Krisan

\begin{tabular}{|c|c|c|c|c|c|c|c|c|c|c|}
\hline \multirow{4}{*}{$\begin{array}{c}\text { Perlakuan } \\
\text { Konsentrasi } \\
\text { Daminozide } \\
0 \text { ppm }\end{array}$} & \multicolumn{10}{|c|}{ Varietas Tanaman Krisan } \\
\hline & \multirow{2}{*}{\multicolumn{2}{|c|}{ Red Remix }} & \multirow{2}{*}{\multicolumn{2}{|c|}{$\begin{array}{c}\text { Reagen } \\
\text { Pink }\end{array}$}} & \multicolumn{2}{|c|}{ Yellow } & \multirow{2}{*}{\multicolumn{2}{|c|}{ Giant White }} & \multirow{2}{*}{\multicolumn{2}{|c|}{$\begin{array}{l}\text { Giant } \\
\text { Yellow }\end{array}$}} \\
\hline & & & & & $\mathbf{P u}$ & & & & & \\
\hline & 0.92 & $\mathrm{k}$ & 0.92 & $\mathrm{k}$ & 1.03 & $\mathrm{ijk}$ & 1.29 & ghi & 1.24 & hi \\
\hline 1500 ppm & 0.94 & $\mathrm{jk}$ & 1.16 & hij & 1.13 & hij & 1.40 & gh & 1.30 & $\mathrm{gh}$ \\
\hline 2500 ppm & 0.97 & $\mathrm{jk}$ & 1.22 & hi & 1.22 & hi & 1.50 & fg & 1.37 & gh \\
\hline 3500 ppm & 1.03 & ijk & 1.25 & hi & 1.70 & ef & 1.79 & de & 1.50 & fg \\
\hline 4500 ppm & 1.21 & hi & 1.30 & gh & 1.79 & $\mathrm{de}$ & 2.23 & $\mathrm{~b}$ & 1.99 & $\mathrm{c}$ \\
\hline $5500 \mathrm{ppm}$ & 1.31 & gh & 2.06 & bc & 1.90 & $\mathrm{~cd}$ & 2.70 & a & 2.19 & $\mathrm{~b}$ \\
\hline
\end{tabular}

Keterangan: Nilai pada baris dan kolom yang sama yang diikuti oleh huruf yang berbeda menunjukkan berbeda nyata berdasarkan uji DMRT pada taraf $5 \%$.

Peningkatan konsentrasi Daminozide terbukti dapat menghambat pertumbuhan tinggi tanaman dan berdampak terhadap diameter batang tanaman yang mengalami peningkatan. Pada tanaman Krisan varietas Red Remix, peningkatan konsentrasi Daminozide hingga mencapai 5500 ppm terbukti dapat meningkatkan diameter batang tanaman sebesar 29,7\% bila dibandingkan tanpa Daminozide. Hasil ini didukung dengan penelitian yang telah dilakukan oleh Rifalasna (2019) bahwa penurunan konsentrasi Gibberelin sebesar 10 ppm memberikan hasil peningkatan diameter batang tanaman krisan sebesar 1,9\%. Untuk mengetahui pengaruh adanya penggunaan Daminozide, maka diperlukan juga uji fisiologis dengan cara mengukur kandungan Gibberelin yang ada pada saat tanaman Krisan masuk masa panen. Kandungan Gibberellin yang ada pada tanaman Krisan dapat dilihat pada gambar dibawah ini : 


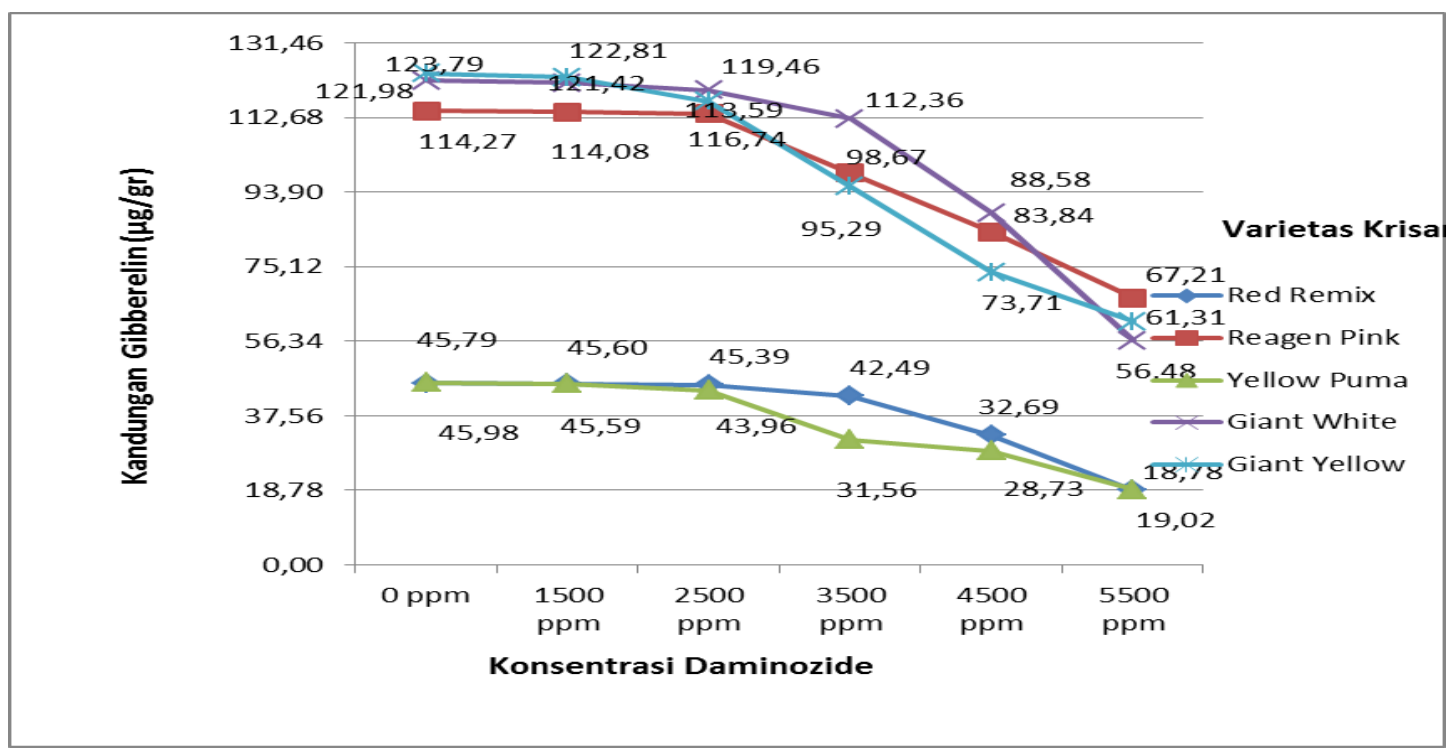

Gambar 1. Grafik Kandungan Gibberelin Pada Seluruh Varietas Tanaman Krisan Dengan Adanya pengaruh Konsentrasi Daminozide yang berbeda

Dari Grafik diatas dapat diketahui bahwa Peningkatan konsentrasi Daminozide dapat berakibat pada penurunan kandungan Gibberelin pada seluruh varietas tanaman Krisan. Kandungan Gibberelin secara normal dapat dilihat pasa saat perlakuan $0 \mathrm{ppm}$ dan mengalami penurunan sebesar 9,23\% saat konsentrasi D pada varietas Red Remix Daminozide ditingkatkan menjadi $3500 \mathrm{ppm}$ dan menurun lagi sebesar $45 \%$ saat konsentrasi Dminozide ditingkatkan hingga mencapai 5500 ppm.

Daminozide mampu menekan pertumbuhan tinggi tanaman dengan cara menghambat sintesis Giberelin. Yamaguchi (2008) menerangkan dalam review nya yang berjudul Gibberellin Metabolism and Its Regulation bahwa Mekanisme sintesis Giberelin diawali dari senyawa $\mathrm{C}_{5}$ isopentenyl diphosphate (IPP) yang disintesis dari Mevalonic acid (MVA). Selanjutnya IPP melalui reaksi katalisis isomerase bentuk dimetyllallyl pentenyl phosphate. Pada kondensasi kepala sampai ekor, 3 molekul IPP secara berurutan ditambahkan pada senyawa ini untuk membentuk difosfat geranyl (GPP), farnesyl difosfat (FPP), dan akhirnya membentuk senyawa $\mathrm{C}_{20}$ geranylgeranyl difosfat (GGPP) yang selanjutnya berubah menjadi ent-kaurene. Pada tahapan hidroksilasi selanjutnya yakni di posisi $2 \alpha$ dimana terjadi konversi bentuk $\mathrm{GA}_{1}$ menjadi $\mathrm{GA}_{8}$ terjadi pengurangan aktivitas biologi dengan drastis. Penggunaan Daminozide pada 
penelitian ini merupakan salah satu zat penghambat tumbuh dengan bentuk struktur acyclohexanedione dan 2-oxoglutaric acid. Struktur daminozide ini melakukan penghambatan tahapan lanjutan setelah terbentuknya $G A_{12}$-aldehid, yakni pada pembentukan $G A_{1}$ dari $G A_{20}$ dan konversi dari $G A_{l}$ menjadi $G A_{8}$.

\section{KESIMPULAN DAN SARAN}

Kesimpulan pada penelitian ini adalah 1)Penggunaan Daminozide terbukti berpengaruh terhadap aktivitas Gibberelin yang ditunjukkan dengan menurunnya tinggi tanaman, meningkatnya diameter batang tanaman dan menurunnya kandungan Gibberelin pada semua varietas Krisan dan 2) konsentrasi daminozide yang terbaik dalam menurunkan aktivitas Gibberelin dalam upaya membentuk Bunga Krisan pot agar memiliki masa simpan yang lebih panjang adalah sebesar 4500 ppm untuk ke lima varietas tanaman Krisan yang telah digunakan.

Diharapkan terjadi keberlanjutan dalam upaya mendapatkan informasi terbaru terkait dengan dampak yang ditimbulkan dalam penggunaan Daminozide. Sehingga untuk penelitian selanjutnya dapat menggunakan parameter penelitian yang lebih banyak dari segi fisiologis tanaman Krisan.

\section{DAFTAR PUSTAKA}

BALITHI. 2016.Laporan Kinerja Hasil Penelitian Tahun 2016. Direktorat Budidaya Tanaman Hias : Jakarta

Kumar, R.,L.C De and Pankaj Basswar. 2019. Production of Cryshanthemum Under Green House Condition. ICAR Research Complex For NEH Region. Meghalaya

Marwoto, B. 2005. Standar Prosedur Operasional Budidaya Krisan Potong. Direktorat Budidaya Tanaman Hias. Direktorat Jenderal Hortikultura. Departemen Pertanian. Jakarta. 
Rifalasna. 2019. Pengaruh Konsentrasi Zpt Giberalin Dan Lama Penyinaran Terhadap Pertumbuhan Dan Hasil Tanaman Krisan (Chrysanthemum Morifolium). J. Agro Complex 3(1):84-9

Salachna. 2017. Effect of Daminozide and Flurprimidol on Growth Fowering and Bulb Yield of Eucomis autumnalis (Mill.) Chitt. Folia Hort. 29/1 : 33-38

Wattimena, G.A. 1988. Zat Pengatur Tumbuh Tanaman. Pusat Antar Universitas. IPB. Bogor. 145

Yamaguchi. 2008. Gibberellin Metabolism and Its Regulation. Annu Rev Plant Biol. 59():225-51 